\title{
Incommensurability in Second Language Acquisition Approaches
}

\author{
GAO Hai-long \\ China Youth University of Political Studies, Beijing, China
}

\begin{abstract}
Researchers in the field of Second Language Acquisition (SLA) have been taking different routes. Some researchers make linguistic-cognitive issues their inquire object and pursue objectivity with quantitative research methods. Other researchers regard the social context of activity as an essential characteristic of learning and teaching. These groups of researchers make use of qualitative research methods like case study, grounded theory, narrative inquiry, and ethnography. There are many other routes that SLA researchers have taken, but the two just mentioned are perhaps the most predominant ones and the ones that are most easily contrasted. The present paper explores the disparity between the different research paths from the perspective of philosophy of science echoing the notion of incommensurability. In this paper the author argues that the differences between different SLA perspectives are not only commensurable but wholesome for the development of SLA.
\end{abstract}

Keywords: SLA, incommensurability, cognitivism, social-cultural approach

\section{Introduction}

Since its beginning the field of Second Language Acquisition (SLA) has been under strong influence from cognitivist tradition that can be traced back to Descartes. The influence from a cognitivist tradition is easily seen in Chomsky's Universal Grammar to SLA (e.g., White, 2003). But alternative approaches in this research field have been rising to the challenge of cognitivism. Unlike cognitivists who adopt a view of learners as computational systems and of learning as information processing, the sociocultural theory approach, to take it as an exam, is based on the psychological theory of human consciousness proposed by Lev Semyonovich Vygotsky. Proponents of sociocultural theory concentrate on if and how language learners develop the ability to use the new language to mediate their mental and communicative activity. Thus they have been misunderstanding each other and have failed to communicate on both sides. This resembles, to a large extent, the notion of incommensurability developed by Kuhn (1962, 1996) and Feyerabend (1962). Incommensurability, to give a brief definition, means researchers working from different paradigms, or research traditions, inevitably talk past each other for they do not share any rational basis to evaluate the claims of the other side. Are the different perspectives in SLA research really incommensurable? Can the gap between them be bridged? This paper reviews the concept of incommensurability and then examines the leading SLA approaches, cognitivism and social cultural theory approach, and some other alternatives, to see how different the approaches are from one another.

GAO Hai-long, associate professor, master, English Department, China Youth University of Political Studies. 


\section{Incommensurability}

Feyerabend and Kuhn independently introduced the concept of incommensurability to the philosophy of science. Feyerabend (1970) argued that frameworks of thought and scientific paradigms can be incommensurable out of three reasons. First, the interpretation of observations is implicitly influenced by theoretical assumptions. Theoretical assumptions have an implicit influence on the interpretation of observations, which leads to the difficulty or even impossibility of describing or evaluating observations independent of theory. Besides, paradigms often have different theoretical assumptions, and about them, intellectual and operational scientific methods lead to valid scientific knowledge. Thirdly, paradigms can found themselves on various assumptions regarding the structure of their research area, and this makes it impossible to compare different paradigms in a meaningful way. Thus to adopt a new theory means to take up a new set of terms. Thus, scientists in different paradigms are making use of different terms (Feyerabend, 1999).

Thomas Kuhn first talked about incommensurability in his book The Structure of Scientific Revolutions. In it, he describes incommensurability as a universal property that defines the relationship between successive paradigms (Kuhn, 1962/1996). In the book, Kuhn wrote: "The historian of science may be tempted to exclaim that when paradigms change, the world itself changes with them" (Kuhn, 1962/1996, p. 137). According to Kuhn, the advocates of different scientific paradigms cannot completely appreciate or understand the other's view point for they are living in different worlds. Incommensurability brings about fundamental problems in communication among supporters of different paradigms.

\section{Two Approaches in SLA}

SLA research has been carried out in different approaches. Some researchers investigate linguistic-cognitive issues employing quantitative research methods (Hulstijn et al, 2014). Some other researchers employ qualitative research methods, such as case study and ethnography, to study the social context of activity which is regarded as a fundamental feature of human knowledge and of learning and teaching (Hulstijn et al, 2014). Other approaches like conversation analysis, action theory, sociocognitive theory, and language socialization regard external learner, even group behavior, not mental states, as the proper domain of inquiry (Atkinson, 2011, p. 18).

Apparently, SLA field has primarily adopted a view of learners as computational systems and of learning as information processing (Atkinson, 2011). According to Long:

Much current SLA research and theorizing shares a strongly cognitive orientation... The focus is firmly on identifying the nature and sources of the underlying L2 knowledge system, and on explaining developmental success and failure. Performance data are inevitably the researchers' mainstay, but understanding underlying competence, not the external verbal behavior that depends on that competence, is the ultimate goal. Researchers recognize that SLA takes place in a social context, of course, and accept that it can be influenced by that context, both micro and macro. However, they also recognize that language learning, like any other learning, is ultimately a matter of change in an individual's internal mental state. As such, research on SLA is increasingly viewed as a branch of cognitive science. (Doughty \& Long, 2003, p. 4)

The sociocultural theory approach is based on the psychological theory of human consciousness proposed by Lev Semyonovich Vygotsky. Proponents of sociocultural theory concentrate on if and how language learners develop the ability to use the new language to mediate their mental and communicative activity. Sociocultural theory research places mediation, either by other or self, at the core of development and use, 
which is how sociocultural theory research differs itself from other SLA approaches (Lantolf, 2011, p. 24).

Stemming from the natural sciences, complexity theory argues that systematic behavior in nature is sometimes complex, dynamic, and self-organizing (Atkinson, 2011, p. 17). This view leads to a major consequence, that is, change and variation are primary: The behaviors change the environment; the system then produce new behaviors to adapt to the new environment. Identity perspectives on SLA adopt insights from critical theory and post-structuralism. Identity perspectives on SLA regard SLA as a contingent process of identity construction. Identity has three major aspects: its multiple, heterogeneous character; its implications for opportunity and power in language learning; and how identities change over time. Basing on linguistic anthropology, language socialization focuses on the engagement of "experts" and "novices" in constructing and responding to macro-level cultural-linguistic norms of conduct (Atkinson, 2011, p. 17). The role of power and inequality in socialization is currently a major focus in this area. Conversation analysis studies how learning emerges in interaction, as social participants go about the daily activities of making sense of each other's talk both in and beyond classrooms. The newest alternative SLA approach, socio-cognitive theory, holds that SLA is an adaptive process, and what is being adapted to, namely environmental conditions, should also be included in conceptualizing SLA.

\section{Differences Between Cognitivism and Its Alternatives}

Cognitivist SLA differs from other approaches in the following three dimensions. The most apparent difference is that cognitivism draws from psychological but the alternative ones from socially oriented explanations for second language learning and other constructs associated. Cognitivism interprets knowledge as existing in the mind, and assumes that learning is an individual accomplishment, and postulates that learning is achieved via stimulus from the environment. In comparison, "the SLA theories regard learning as a social accomplishment and posit that knowledge and learning are socially distributed, have social histories, and are only possible through sociality" (Ortega, 2011, p. 167). For example, in Socio-cultural Theory, language learning is "learning to engage in cognitive mediation in the L2" (Ortega, 2011, p. 167). Language learners progress in a gradual way from relying on collaborative scaffolded L2 activity toward more and more independent forms of regulation.

The second dimension along which cognitivism is different from its alternatives arises out of their view as to whether knowledge exists independent of its context (Ortega, 2011, p. 167). This leads to abstractness or situatedness as their goals respectively. Positing that "knowledge can stand alone, available in and transferable across bounded minds and contexts" (Ortega, 2011, p. 167), cognitivists pursue abstractness as a goal. Comparatively, SLA theorists following a social orientation take situatedness as a value, emphasizing learning as parts involved in greater wholes. Cognitivists make the most of epistemological insights from contextuality, contingency, mutuality, embodiment, and culturalmbeddedness. The microgenetic method in social-cultural theory, the construct of alignment in the socio-cognitive approach, and retrodiction in complexity theory, are examples of the alternatives preferring situatedness in their theoretical or analytical principles.

Whether focusing on entities and objects or actions and processes makes the third dimension of difference between cognitivism and the alternative approach (Ortega, 2011, p. 167). Cognitivism believes in entities and objects and depends very much on taxonomies and categories such as "learner", "language", "native speaker", etc. By comparison, alternative approaches use actions and processes which indicate emergent being and being in action. 
Fleck summarizes three characteristics of incommensurability between cognitivism and sociocultural or socio-cognitive perspective (Young, 2014, p. 29). First, borrowing Wittgenstein's (2001) language-game concept, the constructs (language) used by advocates of one paradigm to describe what appears to them as reality is different from that of another. Second, the phenomena that proponents of one paradigm attend to are concepts of their own thought style, and the questions they ask originate from within their paradigm rather than others. A third characteristic of incommensurability between cognitivist and sociocultural or socio-cognitive perspective is the difference in perceptions. Followers of one paradigm do not perceive what researchers of a different thought style see at all and thus lead to the fact that they do not think in a different way about the same phenomena.

Are the different approaches in SLA research incommensurable? We should ask ourselves questions from the following aspects. First, are the differences between different approaches in SLA research epistemological in nature? If one researcher is relativist and another critical rationalist, then the gap between is not bridgeable because the epistemological stances between them would be incommensurable (Hulstijn, 2014, p. 16). There are epistemological stances that are inevitably incommensurable between social and cognitive theories, Vygotskian and non-Vygotskian approaches, or qualitative and quantitative methods in SLA.

Secondly, to use Jordan's (2004) words here: "Is the difference between two different approaches to theory construction inductive, 'research-then theory' methodology first championed by Bacon, or the deductive 'theory then-testing' approach more typical of Descartes and the seventeenth century rationalist movement" ( $p$. 46).

Some of that disparity may be ascribed to the difference in research methods. Some methods are firmly held within one thought collective but are considered abstruse and are not understood by researchers of a different research perspective. For example, while among proponents of cognitivism, the predominant research method has been quantitative, the numerical methods involving statistical analyses of data from surveys, experiments, and language corpora. By contrast, advocates of social-cultural approach mostly use qualitative research method like case study, ethnography, grounded theory, and narrative inquiry. The differences in research method bring about irreconcilable divergences in the insights of SLA phenomena. "The choice of one method may lead to insights that can then be best studied by a different method" (Hulstijn, 2014, p. 30).

Thirdly, do the two theories enjoy the same object of inquiry? In SLA research field, researchers study the same phenomenon, that is, bilingual cognition (Cook \& Bassetti, 2011). However, some researchers see it as neural activation, while some others try to understand the origin of cognition from the perspective of social interaction, cultural artifacts, and the socioeconomic environment of individuals. Thus, different thought styles see the nature of bilingual cognition in quite different ways. Some claims of a theory do not need empirical investigation (Hulstijn, 2014, p. 18). Unlike critical rationalists, for which falsification of testable claims is the hallmark of inquiry, such a theory mainly is made up of a set of views. Lantolf's materialist approach to psychology is an example in that the approach is proposed as an assumption that cannot be tested within the theory.

\section{Wholesome Diversity}

Why is there a widely perceived gap? The core problem is that "a number of dichotomies that have little to do with one another in principle do largely coincide with the cognitive social dichotomy in practice" (DeKeyser, 2014, p. 6). Take the methodology of language learning research as an example. In SLA research field there 
exist the dichotomies of research methods of quantitative versus qualitative, absolute versus relativist, hypothesis testing versus hypothesis generating, etc. As Robert DeKeyser (2014) says, "Equating all of these dichotomies amounts to confusing material objects (cognitive or social phenomena) with formal objects (aspects of the phenomena most amenable to certain disciplines, methodologies, approaches, etc.; e.g., see Maritain, 2005, p. 67)" (DeKeyser, 2014, p. 6).

But to Hulstijn: “...there does not exist a gap between social and cognitive approaches to L2 learning and teaching insofar as language learning is inherently social and, at the same time, all learning is cognitive by definition" (Hulstijn, 2014, p. 15). Robert DeKeyser (2014) also takes a similar viewpoint (p. 6). According to him, most if not all language learning is accomplished in social and cultural environment which takes effect in the process of learning. At the same time, all learning that takes place in social and cultural contexts is a cognitive process. Cognition is the same thing with knowledge.

Finally, will SLA develop better or worse with the diverse perspectives and research approaches? Lourdes Ortega (2011, p. 167) believes, to which I agree, that SLA has been developing sounder since the social turn. Unique insights into this research field have been accomplished that would have been possible without socially oriented theoretical alternatives. Secondly, multiple and better understandings of SLA have been achieved by the epistemological multiplicity caused by the diverse perspectives of SLA research such as social, socio-cognitive, and cognitive theories. Lourdes Ortega (2011, p. 167) also hold that the diversity of different SLA perspectives, the socially oriented theories in particular, has provideduniquely effective insights into this field. The social perspective on SLA in general "has developed stances and acuteness that uniquely add to the field'scapacities to investigate additional language learning. Other SLA communities need and can benefit from these alternative perspectives" (Lourdes Ortega, 2011, p. 167).

\section{Conclusion}

To conclude, this paper reviews the different research paths in SLA from the perspective of philosophy of science echoing the notion of incommensurability. From the perspective of epistemology, social and cognitive theories are incommensurable as there exist differences between Vygotskian and non-Vygotskian approaches in SLA. Besides, in terms of research methodology, the contrast lies in the fact that cognitivists prefer quantitative while social cultural approach use more qualitative research method. Also, although SLA researchers study the same phenomenon, different thought styles see the nature of bilingual cognition in quite different ways. When taking a deeper insight into the problem, however, the social and cognitive approaches to L2 learning and teaching are not incommensurable at all because all learning that takes place in social and cultural contexts is a cognitive process.

It is the author's belief that SLA will develop better with the diverse or even challenging, on the surface at least, perspectives and research approaches. Unique insights into this research field have been accomplished and multiple and better understandings of SLA have been achieved by the epistemological multiplicity caused by the diverse perspectives of SLA research.

\section{References}

Cook,V., \& Bassetti, B. (2011). Language and bilingual cognition (pp. 143-190). New York: Psychology Press.

Doughty, C. J., \& Long, M. H. (2003). The scope of inquiry and the goals of SLA. In C. J. Doughty and M. H. Long (Eds.), Handbook of second language acquisition (pp. 3-16). Malden, MA: Blackwell.

Atkinson, D. (2011). Cognitivism and second language acquisition. In Alternative approaches to second language acquisition (pp. 
144-166). London: Routlege Press.

Feyerabend, P. K. (1962). Knowledge without foundations, Oberlin, Ohio: Oberlin Printing Co..

Feyerabend, P. K. (1970). Problems of empiricism. UK: Cambridge University Press.

Feyerabend, P. K. (1999). For and against the method. America: University of Chicago Press.

Lantolf, J. P. (2011). The sociocultural approach to second language acquisition. In Alternative approaches to second language acquisition (pp. 24-48). London: Routlege Press.

Hulstijn, J. H., Young, R. F., Ortega, L., Bigelow, M., DeKeyser, R., Ellis, N. C., Lantolf, J. P., ... Talmy, S. (2014). Bridging the gap-Cognitive and social approaches to research in second language learning and teaching. Studies in Second Language Acquisition, 36, 361-421.

Hulstijn, J. H. (2014). Epistemological remarks on a social-cognitive gap in the study of second language learning and teaching. Studies in Second Language Acquisition, 15-20.

Jordan, G. (2004). Theory construction in second language acquisition (pp. 43-46). Amsterdam: Benjamins.

Kuhn, T. S. (1962/1996). The structure of scientific revolutions (3rd ed.). Chicago, IL: University of Chicago Press.

Ortega, L. (2011). SLA after the social turn-Where cognitivism and its alternatives. In Alternative approaches to second language acquisition. London: Routlege Press.

Maritain, J. (2005). An introduction to philosophy. Lanham, MD: Rowland \& Littlefield.

Young, R. F. (2014). Methods and data tangled up in blue. Studies in Second Language Acquisition, 29-37.

DeKeyser, R. (2014). The philosophy of science and the social-cognitive dichotomy in research in language learning and teaching, Studies in Second Language Acquisition, 5-8.

White, L. (2003). On the nature of interlanguage representation: Universal Grammar in the second language. In C. J. Doughty and M. H. Long (Eds.), Handbook of second language acquisition (pp. 19-42). Oxford: Blackwell.

Wittgenstein, L. (2001). Philosophical investigations (3rd ed.). (G. E. M. Anscombe, Trans.). Oxford, UK: Basil Blackwell. 